Isaac Olumayowa Oni

\title{
THE SOCIABILITY OF WEST AFRICAN MIGRANTS AMONG RUSSIANS IN MOSCOW
}

This paper focuses on the social relationships of West African migrants living in Moscow. It investigates the factors to which West African migrants are exposed that promote or limit their social involvement in the new environment in which they find themselves. Although the African community in Russia is rather small, it is gradually increasing. It is, therefore, the aim of this research to examine the effect of the host environment on their perception of the society and how they try to blend in, or not, with social activities there. The article is based on qualitative methods, namely eleven interviews and participant observation of West African migrants. This research revolves around themes such as their communicative language skills, formation of networks among the host community, and sociability. Findings from the research show that West African migrants in Moscow have been attached to their ethnic landscapes, which has limited their sociability in their host society. Since sociability is not mono-directional, the state needs to do more to create both public awareness of the need to recognize and accept the presence of other races and also to create regulations that will guide the smooth integration of migrants in the country.

Keywords: West African migrants, discrimination, interaction, language, sociability, Moscow

DOI: $10.17323 / 727-0634-2020-18-1-143-156$

Isaac Olumayowa Oni- Doctoral Fellow, Doctoral School of Sociology and Junior Researcher, International Laboratory of Social Integration Studies, National Research University 'Higher School of Economics', Moscow, Russia. Email: ioni@hse.ru 


\section{Introduction}

Studies on issues related to African migration to Russia are limited and this segment of migrants remains understudied. Most of the studies on African migration have been focused on other receiving countries such as the United Kingdom, Germany, France, Spain, Canada, the United States of America, Italy, Portugal, Sweden, and the Netherlands (Hamer 2008). As the global mobility of migrants across the globe increases, so does social diversity of various societies, which has amplified the study of multi-cultural dimensions. African migration to the Russian Federation has increased since the disintegration of the Soviet Union. The Soviet era witnessed the arrival of student migrants from Africa, who were to be trained in socialist ideology and, on completion, return to their home countries and implement what they had learned there. However, the break-up of the Soviet Union resulted in another reason for migration to Russia in the shape of labour migration. The figure below shows the variations in the migration flow from Africa to Russia.

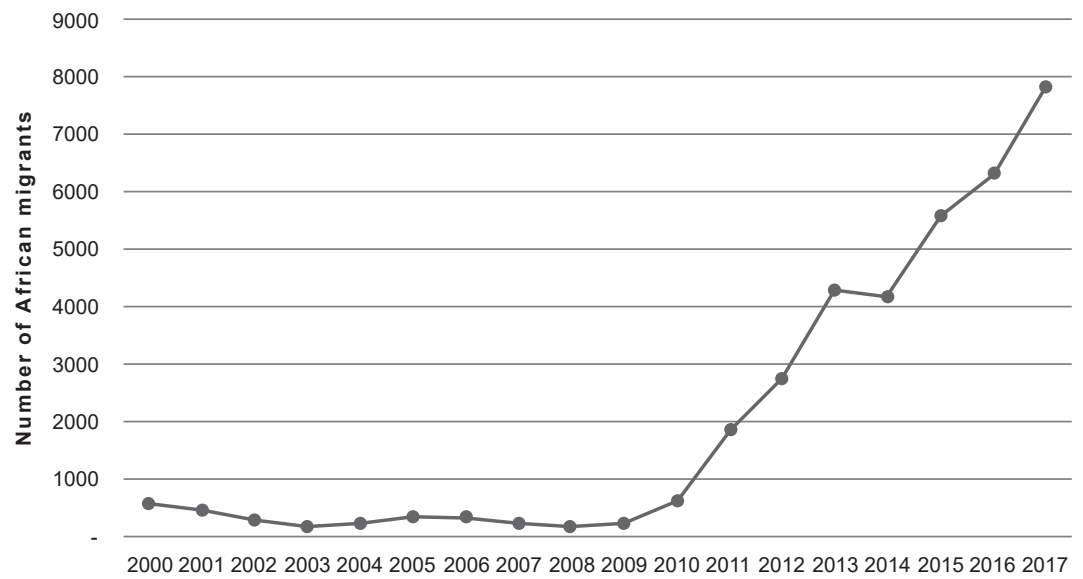

Figure 1: Arrivals of Africans to the Russian Federation

Note: immigration figures refer to the inflow of migrants who have stayed longer than one year. Source: Federal Statistics Service (Rosstat) updated March 15, $2019^{1}$

Many factors contribute to the increasing number of migrants from Africa. These include economic downturns that have increased unemployment and

1 The figures were obtained after a personal request from Rosstat. Due to the small numbers from many African countries, most of them are categorized under the 'Others' category. Only Egypt, Zambia, Morocco and Nigeria are listed on the official statistics. 
poverty as well as political instability, which has contributed to poor policy formulation and implementation, worsening security and increases in violence (Olubiyi, Olarinde 2015). Although Russia is not the primary destination country for the majority of Africans, from 2010 there is an upsurge in the number of Africans migrating to Russia (Fig. 1). A new migration policy that running until 2025 was adopted in 2012. It claims to provide simplified measures of entry into the country, participation in the labour market, along with the expansion and execution of integration programmes, which may include assistance in housing, medical care, and learning of the Russian language so as to prevent foreigners becoming isolated from the way of life in Russia (Chawryło 2012; Mihaylova 2017). However, in relative terms, the African community in Russia is the smallest in comparison to the rest. Out of the total number of 589, 033 arrivals to Russia in 2018, 524,452 were from the Commonwealth of Independent States (CIS) countries, while only 7,833 were from African countries out of the remaining 64,581 arrivals, which are from other countries mostly in Asia, America and Europe (Rosstat 2018). African migration to Russia has not attracted the attention of researchers, which is probably the result of the small size of this group compared to other immigrant groups in Russia.

Many African migrants who came to the USSR to study utilized the opportunity opened to them to stay after the disintegration of the Soviet Union. They switched from being students to labour migrants after the completion of their studies. Some of them got married to Russians while some got employed in multinational companies that began to operate in Russia. Others, who came to Russia with the original intention of using it as an entry point to Western Europe, remained after not being able to gain entry into any country in the West (Vasiliev et al. 2011). Living in a community that is culturally and socially different, migrants are faced with issues that affect everyday life. Feeling a sense of belonging in the social sector of the host society is determined by the level of sociability enjoyed by the migrants.

The concept of sociability according to Cara Flanagan (2002) is the disposition of seeking friendship relationships and to be in the company of others or the desire to associate and interact with a different group (see, also: Amit 2015; Enfield, Levinson 2006). Kurt Wolff (1950) opined that hunger, love, work, religion, technology can be classified as social but sociation is only achieved when isolated individuals or groups are incorporated into the society and share the same interests. Sociability, therefore, reflects a conscious awareness of a particular group to recognize and incorporate the presence of a different group within a territory. This relationship ensures that, having recognized their peculiarities, people of different origins and cultures still interact which can be viewed as strategic way of sociation that ensured both perpetuation of unique cultures and interaction between them. A migrant's sociability can be imagined spatially, whereby the relationships among groups are considered from different social spaces in terms of culture and interactions. 
According to Allison Blakely (1976), black people's presence in Russia can be traced back to the $17^{\text {th }}$ century, indicating a long history of contact between the Russians and Africans. Kesha Fikes and Alaina Lemon (2002) also confirmed the account of the presence of the black people in Russian historical spaces. However, both studies also admit that stereotypical attitudes towards blackness has a long history in Russia. This is reflected in Russian's contemporary perceptions of black people. The image of Africa and Africans have a direct and decisive influence on shaping public opinion about migrants and on actual relations with them (Vasiliev et al. 2011).

The Russian media portrays black people negatively, referring to them as 'poor' and 'dirty' people and those that need help to cater to their basic needs (Bondarenko 2017). These stereotypical projections have shaped the way the people perceive Africans, which is still manifested in the mindset of many Russians, both old and young. I (being a black man) can remember a recent incident with a Russian youth who touched my skin, then put his hand towards his nose to perceive the scent and immediately started using his cloth to clean his hand. Another West African also shared her story with me about a child she met at a restaurant with his parents. When the kid saw her, he started running away saying 'She is dirty'.

The attitude of the host community towards migrants is very important in shaping migrants' perceptions (Bondarenko et al. 2009). Population Services International (2018) reports that migrant behaviour in response to their social interaction is affected by external factors such as interpersonal relations, the community, the physical environment, economic determinants, and the policy framework. Being able to socialize and interact demands a reciprocal system of mutual understanding between the African migrants and Russians. It is a fact that some people are more sociable than others; however, sociability is a characteristic that is common to every individual. This paper seeks to examine the interplay between the West African migrants and Russian society particularly the factors that hinder or promote the sociability among the West African migrants living in Moscow.

\section{Social Interaction Patterns and Choices of the West African migrants in Moscow}

This research is based on detailed fieldwork study conducted from April to June 2019 in Moscow, using qualitative methodology, and centred on eleven semi-structured, in-depth interviews with West African migrants. The English language was used during the interviews, which lasted from 30 to 90 min and were transcribed verbatim. Analysis of the interviews revolves around three main topics: communicative language skills, local networks among the host community, and sociation between West African migrants and Russians living in Moscow. Interviews were supplemented by participant observation at places and 
events attended by West African migrants in Moscow such as churches, birthday parties and symposiums organized by African community organizations.

The selection of the interviewees was based on three categories of West African migrants that I have highlighted. This classification is needed to get different views of the migrants based on the length of stay of the migrants, the changing academic and economic environments in Moscow that they come into. The first category consists of African migrants who had initially come through the Soviet government scholarship programme to study but stayed after the completion of their degrees. They witnessed the transition from the USSR to the Russian Federation. The second category consists of African migrants who are currently doing their doctoral programmes at different universities in Moscow. Compared to the Soviet era, the system of education in Russia has gone through transformation. Some universities now offer programmes in English to make their academic environment more diverse and attractive to international students. This category consists of people who are studying on English taught programmes. The third category consists of people who migrate to Russia for reasons other than education. The collapse of the USSR opened up the Russian economy to accommodate more people into the country to participate in the economic activities. These categories are considered to give an understanding of the distinct experiences of West African migrants coming to Russia during different periods and for diverse reasons.

Thus, in this section, I explore the strategies and patterns of social interactions of the West African migrants in Moscow. I will focus on three scales: communicative language skill, migrants' social networks and sociability.

\section{Communicative Language Skills}

Learning the language of the host country is an important factor that helps to foster communicative integration (Chauhdry 2016). Communicative integration allows migrants to partake in the communicative structure of the host society (Diaz 1993). The significance of language to the effective integration of migrants cannot be underestimated since it constitutes a medium of everyday communication among the people. The interviews reveal that there are distinctions in the process of learning Russian among the West African migrants. For them, learning Russian is paramount because there is no previous colonial connection between the West African countries and Russia. However, in the periods of the 1960s and 1970s, the Soviet Union had become a very important partner to Africa in the struggle against colonial administration and apartheid rule (Arkhangelskaya, Shubin 2013). The Soviet Union played a significant role in ensuring that European colonies' declarations of independence were recognized. By the 1980s, the Soviet Union had bilateral agreements in the economic, cultural and other fields with a lot of West African countries in a quest to foster development.

Furthermore, many West African students were given scholarships to study in the former Soviet Union (ibid). To study in the Soviet Union, West 
African migrants were made to go through preparatory classes, where they were taught the Russian language and culture:

When I arrived in 1988, the Ministry of Education sent me to Belorussia for the preparatory year in Minsk to study the Russian language. After Minsk, I was sent officially to Ukraine to study my specialty which was Fine Chemical Engineering (type I, male, aged 57, Senegalese).

This story was the same among all the interviewees who were recipients of the Soviet government scholarship. During this period, the Russian language was the only means of communication in Soviet universities. So, they were able to have a quick understanding of the language within a short period of time. One of the respondents pointed out:

Within six months of learning the language, I already captured the language, I was already speaking the language very okay. By the ninth month when we got the diploma, I was one of the best (type I, male, aged 55, Nigerian).

However, the dissolution of the Soviet state opened up the Russian economy and also led to a transformation in the education system. Some universities began to introduce English taught programmes to attract both local and international students. In these cases, there was no need for students to complete a preparatory year of learning Russian for students. Since the Russian language is predominantly used for communication, socializing is a challenge for international students in English taught programmes given their poor understanding of Russian:

I believe if I speak and understand the language, I can relate with the students more. Not being able to speak is a form of barrier. And of course, one of the reasons they don't come to me is because maybe I don't understand Russian (type II, male, aged 31, Ghanaian).

The break-up of the Soviet Union also witnessed the arrival of migrants into the new Russian Federation who came for economic reasons. With Russia having no 'working' integration policy that will cater to the needs of the migrants regarding language acquisition (Mukomel 2013); some of these migrants had to engage in self-study of the language for them to be able to do their business transactions. In some other cases, they also use translation applications. As one of the migrants said:

I learned the language via YouTube and like people say, on the street. However, with the nature of my business, the target is Africans but, I still meet with some Russians because, at the point of clearing my goods, I communicate in Russian. What helps me most of the time is using a translation app (type III, male, aged 38, Nigerian).

The acquisitive of communicative language skills of the West African migrants shows a variation among the different categories for this research. 
The means of language acquisition shows the eventuality of having a good understanding of the language, which will become potent in determining the prospect of socializing with the local people. The responses from the respondents reveal that a good communicative knowledge of the language is needed for learning, interacting with people and business transactions.

\section{Migrants' Local Social Network}

I first look at the networks themselves and then migrants' impressions of local people. Migrant social networks are social ties that connect individuals in their home countries or places of destination (Poros 2011). This type of social tie could be in the form of friendship, kinship or neighbourhood relations, social supports, and so on (Entwisle et al. 2007). Migrants' networks exist across transnational boundaries of two or more countries. However, in this article, I am interested in the composition of the migrants' social network in their destination country, in this case, Russia, and with local residents. There are various studies about the existence of African network communities within the Russian Federation (Bondarenko et al. 2009; Bondarenko 2017). My aim is different and it is to look at the social ties that African migrants have with Russians.

Evidence from the interviews shows similar responses across all the respondents when asked if they have Russian friends. For the African migrants, they see their Russian colleagues at school or the workplace as acquaintances:

Talking about people you interact with, you share certain things $<\ldots>$ But if it were to be friends like we normally have in Nigeria, I will say that I do not have. If to the level of interaction, I will say I do have. Mostly, they are people who know each other from school or the people with whom I work together (type I, male, aged 53, Nigerian).

There is a loose bond that exists between the West African migrants and their host community. Judging from the findings of the interviews, the relationship between the West African migrants and their host community is minimal, which has restricted the development of a strong friendship among them. In another response from the interview, 'People I can call friends are Africans, not that I don't have among the Russians' (type I, male, aged 55, Nigerian). This view is also shared by another respondent who said: 'I can't say that I have any Russian as close pals. Most of my friends are mostly Nigerians, two Kenyans and one Zambian' (type II, male, aged 37, Ghanaian).

One of the reasons for this is the racist violence. Past experiences of physical abuse suffered by African migrants make them feel unsafe and Russian prejudices against black people do not allow for trust between Africans and Russians to develop. Even for those who are involved in businesses, they consider their interaction with the Russians just for business transactions:

I only have few friends and the friends that I have are the people that understand my vision. I am not a type that goes about making all kinds of friends. 
I have just a few of them which is strictly on business (type III, male, aged 38, Nigerian).

The second element that I investigated is the perception of African migrants towards Russians. Going by the history of violence that blacks have experienced in Russia, I asked them about their impression of Russians (in particular Muscovites). All the respondents have a positive response which I find worth exploring: 'My impression of Russia is good. They have their own culture and their own interest, things like that. I like that and I am used to them' (type I, male, aged 53, Nigerian). Migrants' positive perception of their host community helps to contribute to the significance attached to the place, which creates a sense of belonging among them (Plöger, Kubiak 2019). Tolerance of the social context in the host country is critical in contributing to migrants' integration (Bakewell, Jónsson 2011).

The length of stay in an area different from the place of origin is very important in this respect and it influences the perception of such environment. Having stayed in Russia for a long period has made them be more open-minded and more tolerant of their host society. Another factor is the intermarriage between the migrants and their host communities. Most of these people have Russian citizenship, which is obtained predominantly through marriage (Bondarenko 2017). For these people, getting the assistance of their Russian families is common and this allows them to have a positive impression of Russians. However, this does not absolve them from societal prejudices. The following statement demonstrates the response of one of the respondents to an instance where he experienced this:

Having lived in Russia for a long time and during the height of physical assaults on blacks, I have learned to create a thick skin against any form of such abuse today. I lived here when blacks were being beaten and molested. Though it is not common, like we had it then, but it is still there (type I, male, aged 53, Nigerian).

According to the other types of respondents, there is a feeling of unwelcomeness inherent in Russians' responses to interactions with the Africans. Bondarenko (2009) traced this attitude among the Muscovites to the socialist period which depicts a negative picture of Africans. According to one of the respondents:

I think most of them do not know the realities of the outside world. Most of them, probably, either they don't want to know about it or they just believe the stories they hear about other people, especially Africa. Sometimes, the way they look at you is intimidating, some of them are also quite friendly. Sometimes, you get on the metro and nobody wants to sit beside you. If one is not careful, one could develop some hatred against them because of all this. They don't know the truth; it is ignorance and it is rather unfortunate (type II, male, aged 31, Ghanaian). 
The routine form of discrimination experienced by African migrants does not allow them to create a close bond with their host community. Another respondent said: 'Most times, they may be very annoying. Like, when you sit with them, they could stand up to sit elsewhere. This is embarrassing' (type III, female, aged 28, Nigerian). This strained feeling has caused West African migrants to create more social connections within their in-group and has limited their interaction with their host community.

\section{Sociability}

Sociability, as explained by Yasuhiro Matsui (2015), is a form of social bonding existing between or among individuals. Social bonding among migrants' networks includes people such as colleagues at school or the workplace, friends, and neighbours (Tatarko et al. 2017). Migrants' sociability determines their level of integration (Marschall, Stolle 2005). It is well established that migration due to political crisis, economic reasons, and environmental causes, among others has increased ethnic diversity in destination countries. However, for the West African migrants, living in Moscow, moving from a tropically hot territory to a colder environment has reduced their sociability. One of the respondents said that: 'Where do I want to go? I would rather stay indoors' (type II, male, aged 31, Ghanaian). When asked how they spend their free time, there were two variants noticeable in the responses. According to one of them:

I have no free time. I am sometimes reading, sometimes doing business, sometimes teaching, I have not enough free time even to sleep. If I sleep for a long time, I will be afraid because many people are waiting for me (type I, male, aged 57, Senegalese).

For African migrants living in Moscow, engaging in multiple streams of income is common. Life in Moscow is quite expensive (Maslova, Chiodelli 2018) transnational migration of highly skilled workers has grown and diversified; as a consequence, residential practices and socio-spatial behaviour of this kind of migrants (the so-called 'expatriates'), which requires them to be involved in many economic activities. In most cases, this does not afford them time to engage in peer interaction with the host community. Another respondent said:

I don't have free time. I work from Mondays to Saturdays and on Sundays, I go to church. When I get home, that is the only time for me to rest, I just have to sleep and I also do some house chores. Whenever I come back from work, I am always tired and won't have any strength to do anything (type III, female, aged 28, Nigerian).

In most cases, staying indoors to compensate for the activities during the week and getting refreshed for the coming week is the reason why some of them would rather be alone. In the other variant of responses, the inability to 
have a cordial relationship with their Russian colleagues is due to their lack of knowledge of the Russian language, which has prevented them from creating social bonds with their colleagues. This point was discussed in the first subsection above.

The lifestyle of some of the West Africans in Moscow does not allow them to have a social life. When asked a similar question about how they spend their free time, one of the interviewees replied by saying 'In my bed. If I am bored and I miss home, I just watch West African movies, YouTube videos, stuffs going on in Ghana, news and so on' (type II, female, aged 31, Ghanaian). Thus, the interviewees are preoccupied with economic activities and would rather perform their economic duties than have a social life. Another aspect that has limited the West African sociability is not having networks among local people. Their dearth of the Russian language has constrained them from socializing, which has confined them to be alone.

\section{Discussion}

My analysis of the sociability patterns of the West African migrants in Moscow has shown that West Africans in the different categories have different experiences of integration into Russian society. The African community in Russia is growing and it is likely that the trend will continue. In the Soviet period, migrants from West African countries (also from Africa in general) were predominantly students who were made to go through the compulsory one-year language course before they began their main study, which was also conducted in Russian. They (type I in our case study) have a good understanding of Russian. For the type II category, having enrolled in English taught programmes and thus not having studied the Russian language, they find it difficult to engage with their colleagues and integrate into the larger society. However, compared to the Soviet era, there has been a reduction in the number of students from Africa coming to Russia (Bondarenko 2017). What this implies is that the increase in the number of African migrants coming to Russia is due to an increase in the number of people who are coming to Russia for economic reasons. This is type III in my classification and this category had to learn the Russian language on their own, which limited their ability to interact with the people.

In most cases, compared to the Soviet student migrants from Africa, the type III (economic or transit migrants) and type II categories are more advanced in age at the point migration. Their ages range between 28 and 38 years. As indicated by Hartmut Esser (2006), the age of migration is an important factor in language acquisition. Furthermore, there is no institutional provision for migrants coming to the country to study the language and then become integrated into the society; socializing in such an environment thus becomes arduous. As pointed out by Vladimir Mukomel (2013), Russia does not have an integration policy aimed at including migrants into the society. Sociation becomes easier in an environment 
where there is a policy formulated and implemented to foster the incorporation of migrants into the society which is not the case here.

Another factor that inhibits the acquisition of the Russian language among the West Africans is the high degree of ethnic concentration that they have within their networks (Esser 2006). Living among individuals who share the same ethnic origin allows communication in the language of origin and limits the chances of acquiring the language of the receiving country. The inability to communicate in the Russian language is a major contributor to the social strain experienced by the West African migrants. This has limited their chances of making friends with Russians; instead, they connect with people who share the same language. It is clear that, since only in a few number of places will you find Russians who speak the English language, the West African migrant who does not have networks among the locals would be isolated and find it difficult to interact. To build a strong bond in Moscow, migrants need to interact with the locals. Being incorporated into the larger ethnic group is not only about acceptance and being noticeable but also about interacting in public places (Wessendorf 2019). All the categories of migrants in this research project have close relationships with other Africans. West African migrants interact more with people they share similar culture which has limited their social circle within the host society.

However, sociability is not only the prerogative of the West African migrants. Migrant's sociability is a bipartite process. It is determined by both people's characteristics and by the characteristics of the environment they find themselves in (Snyder, Ickes 1985). The host environment is also embedded in this process which is determined by the state policy and people. The attitude of the host community towards migrants shapes migrants' perception of the society and, therefore, impacts their sense of inclusion. The long history of abuse suffered by black people in Russia is very important in influencing the perceptions of the environment by West African migrants. Such perceptions result in insecurity by these migrants and a sense of alienation from the society which makes sociation difficult (Krzyżanowski, Wodak 2008). As earlier pointed out, the absence of a 'working' integration policy is another factor that affects the ability to social interaction. The formulation of policies that will foster both the social and economic participation of migrants might also influence the way local people view the migrants.

\section{Conclusion}

This research is centred on the social relationship patterns of West African migrants in Moscow. It shows that these migrants tend to segregate themselves from social interaction with their host community. Although the personal lifestyles of West African migrants in Moscow are a crucial element to consider, in this regard, there are external mechanisms of language which to a large extent are an important determinant of social interaction. 
From the evidence revealed in the research, lack of knowledge of Russian is a barrier to interaction between West African migrants and Russians. They also do not identify with the culture of the local people but rather have more inclination to socialize with people who share the same culture and skin colour, which distances them from the larger ethnic group and limits their social interaction with the host community. Also contributing to the limited interaction between the West African migrants and their host community are external factors such as the history of discrimination against the black people and the feeling of discrimination some of them have. The absence of policies to encourage the smooth integration of migrants is an institutional arrangement that limits their sociability.

\section{Acknowledgment}

The article was prepared within the framework of the Basic Research Program at HSE University and funded by the Russian Academic Excellence Project '5-100'.

\section{References}

Amit V. (2015) Thinking Through Sociality: An Anthropological Interrogation of Key Concepts. New York: Berhahn Books.

Arkhangelskaya A. A., Shubin V. (2013) Russia's Africa Policy. Johannesburg: South African Institute of International Affairs.

Bakewell O., Jónsson G. (2011) Migration, Mobility and the African City. Available at: https:// pdfs.semanticscholar.org/d2b5/8ffc00992adf067760ad0790b4f78c2f7c86.pdf (accessed 15 October 2019).

Blakely A. (1976) The Negro in Imperial Russia: A Preliminary Sketch. The Journal of Negro History, 61 (4):351-361.

Bondarenko D. M. (2017) African Migrants in Post-Soviet Moscow: Adaptation and Integration in a Time of Radical Socio-Political Transformations. Irinkèrindò: A Journal of African Migration, (9): 35-75.

Bondarenko D., Googueva E., Serov S., Shakhbazyan E. (2009) Post-socialism Meets Postcolonialism. Anthropological Journal of European Cultures, 18 (2): 87-105.

Chauhdry F. (2016) Integration Through Language Learning. Oslo: University of Oslo.

Chawryło K. (2012) A New Concept of Migration Policy in Russia. Available at: https://www. osw.waw.pl/en/publikacje/analyses/2012-06-20/a-new-concept-migration-policy-russia (accessed 15 October 2019).

Diaz J. (1993) Choosing Integration: A Theoretical and Empirical Study of the Immigrant Integration in Sweden. PhD Thesis. Department of Sociology, Uppsala Universitet. 
Enfield N., Levinson S. (2006) Roots of Human Sociality. New York: Berg.

Entwisle B., Faust K., Rindfuss R., Kaneda T. (2007) Networks and Contexts: Variation in the Structure of Social Ties. American Journal of Sociology, 112 (5): 1495-1533.

Esser H. (2006) Migration, Language and Integration. Berlin: AKI Research Review.

Fikes K., Lemon A. (2002) African Presence in Former Soviet Spaces. Annual Review of Anthropology, 31 (1): 497-524.

Flanagan C. (2002) Early Socialisation: Sociability and Attachment. New York: Taylor \& Francis.

Hamer M. (2008) Migration Patterns and Influence of Support Networks: A Case Study of West Africans in the Netherlands. Gender, Technology and Development, 12 (3): 347-364.

Krzyżanowski M., Wodak R. (2008) Multiple Identities, Migration and Belonging: 'Voices of Migrants.' In: C. Caldas-Coulthard, R. Iedema (eds.) Identity Trouble. Basingstoke: Palgrave Macmillan:95-119.

Marschall M., Stolle D. (2005) Seeing or Living Diversity: Contact with Diverse Others and the Development of Generalized Trust. CPSA Annual Conference, London, Ontario.

Maslova S., Chiodelli F. (2018) Expatriates and the City: The Spatialities of the High-skilled Migrants' Transnational Living in Moscow. Geoforum, (97): 209-218.

Matsui Y. (ed.) (2015)'Obshchestvennost' and Civic Agency in Late Imperial and Soviet Russia. Basingstoke: Palgrave Macmillan.

Mihaylova I. (2017) Russia's New Concept of the State Migration Policy Until 2025: A Reform Towards Effective Policies for International Economic Migrants? Geopolitics, History, and International Relations, 9 (1): 176-214.

Mukomel V. (2013) Integration of Migrants: Russian Federation. Florence: European University Institute.

Olubiyi E., Olarinde O. (2015) Emigration and Labour Market Dynamics in Nigeria. Conference on Migration Policy Thematic Areas, International Organization for Migration, Abuja, Nigeria.

Plöger J., Kubiak, S. (2019) Becoming 'The Internationals' - How Place Shapes the Sense of Belonging and Group Formation of High-Skilled Migrants. Journal of International Migration and Integration, 20 (1):307-321.

Poros M. (2011) Migrant Social Networks: Vehicles for Migration, Integration, and Development. Available at: https://www.migrationpolicy.org/article/migrant-social-networks-vehicles-migration-integration-and-development (accessed 15 October 2019).

Population Services International (2018) About Social \& Behaviour Change. Available at: https://asbc-conference.org/about-social-and-behaviour-change/ (accessed 15 October 2019).

Rosstat (2018) Federal State Statistic Service. Available at: https://eng.gks.ru/, accessed on: 2019-11-0622:16:28 (accessed 15 October 2019). 
Snyder M., Ickes W. (1985) Personality and Social Behavior. Handbook of Social Psychology, 2 (3): 883-947.

Tatarko A., Mironova A., van de Vijver F. J. R. (2017) Ethnic Diversity and Social Capital in the Russian Context. Journal of Cross-Cultural Psychology, 48 (4): 542-559.

Vasiliev A., Abramova I., Bondarenko D., Ksenofontova N., Ivanov A., Amvrosova M. (eds.) (2011) African Studies in Russia Yearbook 2008-2009. Moscow: Russian Academy of Sciences, Institute for African Studies.

Wessendorf S. (2019) Migrant Belonging, Social Location and the Neighbourhood: Recent Migrants in East London and Birmingham. Urban Studies, 56 (1): 131-146.

Wolff K. (1950) The Sociology of Georg Simmel. New York: Simon and Schuster. 